\title{
BENEFÍCIOS DO PIBID NA FORMAÇÃO DE ESTUDANTES DO CURSO DE LICENCIATURA EM EDUCAÇÃO FÍSICA: UMA REVISÃO BIBLIOGRÁFICA
}

\author{
Eliaquim de Sousa Lima, Jayane de Oliveira Rodrigues, Francisco Diogo da Silva Rocha, \\ Cesar Augusto Sadalla Pinto
}

\author{
Instituto Federal de Educação, Ciência e Tecnologia do Ceará (IFCE) \\ <eliaqumsousa@hotmail.com><jayaneorodrigues@hotmail.com> \\ <diogorocha460@gmail.com><cesarsad@gmail.com>
}

DOI: $10.21439 /$ conexoes.v13i1.1526

\begin{abstract}
Resumo. A formação de professores é marcada por desafios entre a distância da teoria e da prática, com isso, políticas educacionais necessitam surgir com intuito de superar as dificuldades existentes na formação. $O$ Programa Institucional de Bolsas de Iniciação à Docência (Pibid) é uma dessas políticas, tendo sido implantado no ano 2007, intentando possibilitar aos alunos das licenciaturas: vivências e experiências na docência. Partindo disso, objetivou-se analisar as contribuições do Pibid para a formação dos estudantes do curso de licenciatura em Educação Física. A partir de uma revisão bibliográfica, realizou-se uma discussão sobre a temática. Os resultados demonstram que o Pibid contribui para a aproximação do aluno de seu futuro campo de atuação, a escola, dando significativa contribuição para a sua formação prática do estudante. Além disso, o programa de iniciação à docência proporciona um olhar reflexivo do estudante sobre os aspectos da docência e permite o reconhecimento da Educação Física como disciplina escolar. Conclui-se que o Pibid é importante como política pública de qualificação da formação de professores, particularmente na área da Educação Física.
\end{abstract}

Palavras-chave: Pibid. Formação de Professores. Educação Física.

\section{BENEFITS OF PIBID IN THE TRAINING OF STUDENTS OF THE LICENSEE COURSE IN PHYSICAL EDUCATION: A BIBLIOGRAPHIC REVIEW}

\begin{abstract}
The training of teachers is marked by challenges between distance from theory and practice, with this, educational policies need to arise in order to overcome the difficulties in training. The Institutional Scholarship Initiative Program (Pibid) is one of these policies, and was implemented in 2007, trying to make it possible for undergraduate students: experiences and experiences in teaching. Based on this, the objective was to analyze the contributions of the Pibid for the training of undergraduate students in Physical Education. From a bibliographical review, a discussion on the subject was held. The results demonstrate that the Pibid contributes to the student's approximation of his future field of activity, the school, giving a significant contribution to his practical student training. In addition, the teaching initiation program provides a reflective student look at aspects of teaching and allows the recognition of Physical Education as a school discipline. It is concluded that the Pibid is important as a public policy for the qualification of teacher training, particularly in the area of Physical Education.
\end{abstract}

Keywords: Pibid. Teacher training. Physical. Education. 


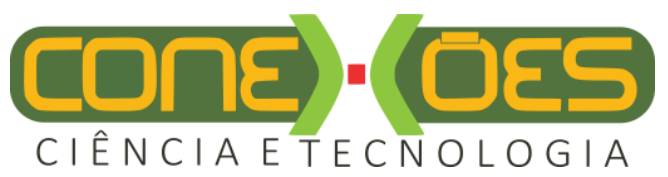

\section{INTRODUÇÃO}

O percurso acadêmico é marcado por enormes desafios que devem ser enfrentados a fim de que os graduandos se tornem indivíduos cada vez mais capacitados para realizarem a sua prática profissional. Nas licenciaturas, por exemplo, o distanciamento entre a universidade e a escola ainda é um desafio a ser superado, o qual tem ocasionado muitas vezes uma formação descontextualizada, pois os estudantes adquirem poucas oportunidades para que possam se familiarizar com o seu futuro ambiente de trabalho (AMBROSETI et al., 2013).

Apesar dos cursos de licenciatura estimularem o contato dos estudantes universitários com o espaço escolar através dos Estágios Supervisionados e das Práticas como Componente Curricular, é essencial que outras atividades sejam vivenciadas no decorrer da graduação com o intuito de fomentar a formação prática dos futuros professores, ao mesmo tempo em que há o aperfeiçoamento das atividades curriculares já consolidadas.

Segundo Trajano (2015), historicamente a Educação Física tem sido desvalorizada e quase exclusivamente desenvolvida como prática de esportes, faltando, em muitas situações, reflexão por parte dos professores sobre a necessidade de diversificar as metodologias e conteúdos do processo ensino-aprendizagem. Essa situação demarca a existência de uma formação deficitária, sendo importante qualificar a formação do professor de Educação Física. Nesse aspecto, as ações de iniciação à docência podem ter um papel de destaque, não sendo as únicas, mas podendo contribuir para a melhoria do processo formativo e valorização do magistério.

O Pibid tem como foco possibilitar aos estudantes das licenciaturas vivências na docência para que possam conhecer e explorar a sua futura profissão. Além disso, de forma complementar ao currículo universitário, proporciona o contato do estudante com a escola, com os sujeitos que fazem parte do seu cotidiano (funcionários e alunos) e com as suas rotinas, contribuindo para o enriquecimento de sua formação por meio da articulação entre teoria e prática (STANZANI; BROIETTI; PASSOS, 2012).

Desta forma, questiona-se que contribuições o Pibid pode proporcionar aos estudantes do curso de Licenciatura em Educação Física? Essa questão central guiou a realização do estudo, que teve como objetivo analisar as possíveis contribuições do Pibid na formação dos estudantes do curso de Licenciatura em Educação Física. Para isso, utilizou-se a pesquisa bibliográfica como metodologia de trabalho.
Este trabalho torna-se relevante pela necessidade de explorar as informações sobre a importância do Pibid na carreira profissional docente de estudantes universitários, estimulando reflexões sobre as possíveis contribuições do programa na formação dos estudantes das licenciaturas, particularmente na área da Educação Física. O trabalho pode ainda nortear e embasar futuros graduandos da área que tenham interesse em pesquisar sobre essa temática, considerando que a sistematização do conhecimento produzido sobre o Pibid poderá ser importante para compreender os efeitos dessa política de formação.

\section{A REVISÃO DE BIBLIOGRÁFICA COMO METODOLOGIA}

O trabalho se desenvolveu a partir de pesquisas exploratórias realizadas no portal Google Acadêmico (https://scholar.google.com.br), com o uso dos descritores "Pibid e educação física", "Benefícios do Pibid na Educação física" e "Contribuições do Pibid na Educação Física". A escolha dos descritores teve o intuito de afunilar os resultados da pesquisa exploratória de acordo com o objetivo da pesquisa, entretanto o estudo não se caracteriza como revisão sistemática. Trata-se de um trabalho de revisão bibliográfica do tipo narrativa, que se caracteriza por seu caráter descritivodiscursivo e por uma ampla discussão de temas de interesse científico a partir de fontes de referência (MUÑOZ, 2002, p. 1).

A partir das buscas na internet, 10 trabalhos receberam tratamento analítico por alinharem-se com a temática da pesquisa (ASSIS, 2016; TRAJANO, 2015; OLIVEIRA; BARBOSA, 2013; RAUSCH; FRANTZ, 2013; RIBEIRO; AFONSO; CAVALLI, 2013; AMBROSETTI et al., 2013; STANZANI; BROIETTI; PASSOS, 2012; WELTER; WELTER; SAWITZKI, 2012; MARCON; NASCIMENTO; GRAÇA, 2007; BENITES; NETO, 2005).

Buscou-se também evidenciar referenciais clássicos da área da Educação (GARCÍA, 1999; LIBÂNEO, 1999; TARDIF, 2002) e da Educação Física (BETTI, 1991; CASTELLANI FILHO, 1988; DARIDO, 2003; FREIRE, 1989; GHIRALDELLI JÚNIOR, 1991; SOARES et al., 1992; SOARES, 2007), acessíveis aos autores e indicados por pesquisadores experientes.

Além dos trabalhos apresentados, foi realizada análise de uma monografia defendida no âmbito do curso de Licenciatura em Educação Física do IFCE, campus Limoeiro do Norte (LIMA, 2015), a qual é o único trabalho produzido na base da dados consultada que trata sobre as contribuições do Pibid para a formação do professor de Educação Física. 


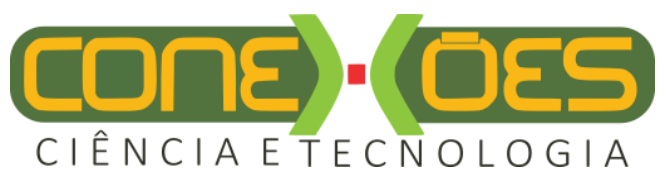

Os referenciais apresentados constituem a base teórica por meio da qual buscou-se refletir sobre os impactos do Pibid para a formação dos professores de Educação Física. Os resultados da revisão bibliográfica são apresentados na próxima seção, evidenciando o contexto histórico da Educação Física escolar e a formação do professor, a formação dos estudantes das licenciaturas e a necessidade de articulação entre teoria e prática, a formação de professores no âmbito do Pibid como possibilidade de articulação entre teoria e prática e as contribuições do Pibid para o licenciando em Educação Física.

\section{FUNDAMENTAÇÃO TEÓRICA}

\subsection{O CONTEXTO HISTÓRICO DA EDUCAÇÃO FÍSICA ESCOLAR E A FORMAÇÃO DO PROFESSOR}

Essa seção dedica-se a explanar o histórico da Educação Física, buscando conhecer o processo de desenvolvimento da área, já que atualmente, imbuída por pensamentos não só do saber fazer e da influência médico-higienista, é possível que se analise essa disciplina como um componente curricular obrigatório (BRASIL, 1996), sendo necessário dos professores formação teórica e prática, capacidade de planejar e organizar o processo ensino-aprendizagem, entre outras posturas docentes. As dimensões pedagógicas e críticas, tão essenciais para um professor que atua na escola, até pouco tempo atrás não se faziam presentes na Educação Física, uma vez que o foco era a prática, isto é, o saber fazer.

A Educação Física é inserida no meio escolar no Brasil em 1851 com a implantação da reforma Couto Ferraz, posteriormente, após a aprovação da reforma do ensino primário e secundário, a ginástica e a dança passaram a ser obrigatórias (DARIDO, 2003). Por volta de 1882, Rui Barbosa contribuiu significativamente para a consolidação da Educação Física escolar, pois além de defender a prática da ginástica para ambos os gêneros (algo bastante incomum neste período), ainda enfatizava a importância da disciplina para o desenvolvimento do sujeito (BETTI, 1991).

Darido (2003) aponta que a Educação Física concebida como ginástica fora influenciada pelos métodos ginásticos surgidos na Europa, principalmente o Sueco, o Francês e o Alemão. Outrossim, as tendências com foco na preparação para as guerras (militarismo) e assepsia dos corpos (higienismo) também trouxeram características específicas para a área nessa época. O higienismo voltava-se para a construção de corpos moralmente e fisicamente limpos, bem cuidados, isentos de doenças, enquanto que a Educação Física induzida pelo militarismo tinha o objetivo de desenvolver corpos fisicamente fortes, preparados para lutar pela nação nas guerras (SOARES, 2007; SOARES et al., 1992). Acrescentando a essa discussão, Darido (2003, p. 2) afirma que:

\begin{abstract}
Ambas as concepções higienista e militarista [...] consideravam a Educação Física como disciplina essencialmente prática, não necessitando, portanto, de uma fundamentação teórica que lhe desse suporte. Por isso, não havia distinção evidente entre a Educação Física e a instrução física militar.
\end{abstract}

Nas décadas de 1940 e 1970, surgem tendências de cunho pedagógico e esportivista, respectivamente. A primeira representada pelo movimento da Escola Nova que eclodiu em 1930 com a ideia de uma educação comprometida com o desenvolvimento pleno, integral das crianças, sendo a Educação Física entendida como "meio" para a concretização dessa educação. A concepção esportivista, por sua vez, foi predominante no período histórico da ditadura militar, a partir de 1964, intentando, a partir das práticas de esportes, formar indivíduos que representassem o país nas competições nacionais e internacionais, a fim de transmitir para os estrangeiros e os cidadãos brasileiros mediante as vitórias e o ganho de medalhas, que o país estava progredindo em outras dimensões da vida social. Portanto, a Educação Física como disciplina escolar tinha a missão de formar atletas e desvendar talentos, valorizando nas aulas o rendimento, a performance e a técnica perfeita dos alunos (BETTI, 1991; GHIRALDELLI JÚNIOR, 1991; CASTELLANI FILHO, 1993).

$\mathrm{Na}$ década de 1980, surgem os movimentos renovadores da Educação Física, com a finalidade de superar o esportivismo, que não considerava a totalidade dos sujeitos e possuía um caráter eminentemente mecanicista (SOARES et al., 1992). Nesse contexto, surge a tendência crítico-superadora da Educação Física, idealizada por um grupo de autores que promoveu uma visão mais crítica da área, focando em um aluno capaz de pensar, refletir, debater e reconhecer as condições históricas da cultura corporal e de sua classe, visando a superação das injustiças sociais.

A história da formação docente na área da Educação Física é recente, visto que apenas em 1939, com a Escola Nacional de Educação Física e Desporto, introduziu-se um curso de didática com temporalidade de um ano para que o profissional possa atuar no magistério (BENITES; NETO, 2005).

A formação em Educação Física ao longo de sua história foi fortemente marcada por influências de 


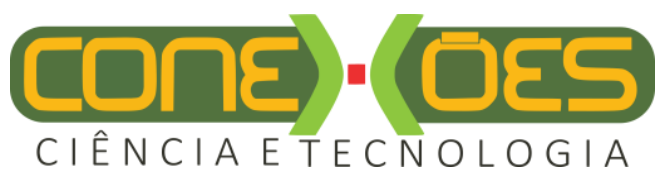

instituições militares e pelo discurso médicohigienista (SOARES, 2007; CASTELLANI FILHO, 1988). A mudança dessa realidade aconteceu de forma gradual, sendo significativas as influências dos movimentos renovadores da Educação Física e das tendências críticas.

Por meio das discussões, percebe-se que o histórico de inserção da Educação Física na escola e a formação dos profissionais da área, foi marcado por abordagens de cunho prático (militarismo, higienismo e esportivismo), acarretando uma visão reduzida que impacta até os dias atuais na construção da identidade e legitimidade dessa no meio escolar, provocando dificuldades da atuação dos professores no que tange a articulação entre teoria e prática. Mesmo o surgimento de tendências pedagógicas e críticas não tiveram os seus efeitos imediatos para a mudança da prática do professor de Educação Física, bem como em seu processo formativo.

\subsection{A FORMAÇÃO DOS ESTUDANTES DAS LICENCIATURAS E A NECESSIDADE DE ARTICULAÇÃO ENTRE TEORIA E PRÁTICA}

A formação dos professores, consiste em um processo de vivências, experiências, desafios, enfrentados durante a formação inicial e, posteriormente, na atuação profissional por meio da formação continuada. Pode ainda "[...] constituir-se em uma ação que exige saberes e fazeres específicos que definem, por assim dizer, o 'espaço' de atuação de uma determinada profissão" (GARCÍA, 1999, p. 418).

Segundo Tardif (2002) há uma defasagem grande da universidade quanto à formação docente, tendo em vista que os acadêmicos passam bastante tempo a assistir aulas e, em seguida, nos momentos dos estágios e práticas curriculares, passam a "aplicar" os conhecimentos adquiridos. Além disso, o autor ressalta que o currículo das instituições de ensino superior valoriza o conhecimento teórico distanciado da situação prática da escola, formando profissionais carentes da associação entre o saber (teoria) e o saber fazer (prática).

A inserção do estudante das licenciaturas no seu futuro ambiente de trabalho, a escola, é um dos desafios e ao mesmo tempo um dos pontos mais importantes para consolidar uma formação com mais qualidade, afinal, os conhecimentos e experiências da universidade, apesar de imprescindíveis, não garantem que os futuros professores adquiram competências e habilidades necessárias a sua prática profissional (LIMA, 2015).

A esse respeito, Marcon, Nascimento e Graça (2007, p. 13) afirmam que:
[...] a oportunidade de conhecer pessoalmente o ambiente escolar, com o olhar do professor em formação, e não mais como um aluno, juntamente com a utilização das atividades de prática pedagógica nas aulas dos cursos de Licenciatura em Educação Física, são apresentados como fatores determinantes para alcançar os objetivos estabelecidos para a formação inicial.

Para Libâneo (1994) a união entre teoria e prática é importante na formação do professor, pois o licenciando ao aprender os conhecimentos teóricos pode refletir na prática até que ponto esses serão transmitidos e assimilados, trazendo implicações para o próprio acadêmico que norteará sua atuação profissional no futuro.

Diante das dificuldades que o processo de formação prática dos professores tem enfrentado, o Ministério da Educação (MEC) aponta que a mudança necessita acontecer nas unidades formadoras através da estruturação dos conteúdos de atuação do professor, do processo de organização institucional e da vinculação entre universidade e sistema de ensino, possibilitando a qualificação da formação inicial para o exercício da docência. Nesse sentido, o Pibid pode contribuir positivamente na formação dos futuros professores (TRAJANO, 2015)

A busca pela aproximação entre teoria e prática no processo formativo é defendido por muitos teóricos da área da Educação Física (RANGELBETTI; BETTI, 1996; DARIDO, 1995; FREIRE, 1989). A formação de professores, seja inicial ou continuada, necessita vislumbrar novos rumos para tornar sólida futuramente a atuação dos estudantes, por isso supõe que tanto a universidade necessita repensar seu processo pedagógico, como a própria instituição escolar deve fornecer condições para que os licenciandos possam se inserir na escola e os professores em exercício continuem agregando conhecimentos para a melhoria de sua prática pedagógica, na qual teoria e prática sejam compreendidas como uma unidade.

Reafirma-se que um estreitamento dos laços entre a universidade e a escola é necessário, permitindo ao professor conhecer, vivenciar e sentir o seu futuro ambiente de trabalho ainda na graduação, e aos professores que se encontram em exercício terem oportunidade de transitar entre o seu próprio ambiente de trabalho e a universidade para trocar conhecimentos e experiências com professores e alunos que lá se encontram. 


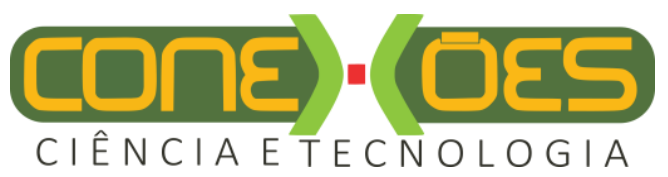

\subsection{A FORMAÇÃO DE PROFESSORES NO ÂMBITO DO PIBID COMO POSSIBILIDADE DE ARTICULAÇÃO ENTRE TEORIA E PRÁTICA}

O Programa Institucional de Bolsas de Iniciação à Docência (Pibid) é resultado de uma política nacional para a melhoria da formação docente em articulação com a educação básica. Em 2007, o MEC lançou o primeiro edital do Pibid, entretanto as atividades do programa só iniciam em 2009, sob a égide institucional da Coordenação de Aperfeiçoamento de Pessoal de Nível Superior CAPES (RAUSCH; FRANTZ, 2013). Entre os objetivos do Pibid destaca-se a busca por contribuir para a articulação entre teoria e prática nos cursos de formação de professores, por meio da inserção dos licenciandos no cotidiano das escolas da rede pública (BRASIL, 2010).

Lima (2015) destaca que a implantação do Pibid no Instituto Federal de Educação, Ciência e Tecnologia do Ceará (IFCE) aconteceu a partir do edital lançado em 2007, com a implantação do programa de iniciação docente em 21 cursos de licenciatura da instituição. No ano de 2012, houve a implantação do subprojeto Pibid Educação Física no IFCE, campus Limoeiro do Norte, proporcionando importantes contributos para a formação inicial dos bolsistas de iniciação à docência, com destaque para o contato com a realidade escolar e as vivências que articulam teoria e prática. Além disso,

\footnotetext{
Os sujeitos da pesquisa relataram que o Pibid tem oportunizado o desenvolvimento de competências e habilidades pedagógicas, tais como capacidade de planejamento, o desenvolvimento de metodologias, a melhoria da postura em sala de aula, melhoria do trabalho em equipe, o contato com atividades de pesquisa, entre outros (LIMA, 2015, p. 30-31).
}

Esse resultado converge com aquele encontrado por Assis (2016), que destaca a existência de impactos significativos do Pibid nas escolas e no ensino superior. Os dados dessa pesquisa demonstram que $64 \%$ dos egressos do Pibid estão atuando no âmbito da Educação, além das mudanças qualitativas que o programa promoveu nas aulas. De acordo com a autora, observou-se ainda uma melhoria no rendimento dos licenciandos, pois o Pibid promove a construção da identidade profissional a partir da realização de reflexões sobre a prática docente conforme suas experiências mediante ao que é vivenciado.

Além das contribuições relatas, o Pibid tem se constituído um evidente campo de estudos e pesquisas sobre a formação e prática do professor. Como campo de pesquisa tem sido utilizado para o fornecimento de diagnósticos sobre a atual situação das escolas e reflexões sobre as práticas formativas, os quais têm sido divulgadas em eventos dedicados a promover o compartilhamento desses saberes. Oliveira e Barbosa (2013, p. 145), ao tratar particularmente do campo de ensino da Sociologia, mas com possibilidade de transposição para outras áreas, evidenciam a importância do desenvolvimento de pesquisas para a articulação entre teoria e prática "sendo condição sine qua non para pensarmos um processo de mudanças mais amplas das Ciências Sociais em torno da formação de professores na área".

\subsection{AS CONTRIBUIÇÕES DO PIBID PARA O LICENCIANDO EM EDUCAÇÃO FÍSICA}

Estudos realizados por Rausch e Frantz (2013) sobre as contribuições do Pibid para estudantes dos cursos de licenciatura em Letras, Química, Ciências Sociais, Pedagogia e Educação Física, constataram, a partir dos relatos dos educandos, que o Pibid propiciou o desenvolvimento profissional docente. Um dos estudantes do curso de Licenciatura em Educação Física relata que o programa fomentou o confronto entre a teoria adquirida na faculdade e a prática vivenciada no âmbito escolar durante as ações do Pibid.

Além de promover a articulação entre teoria e prática, o Pibid apresenta-se como um dos meios capazes de contribuir para o reconhecimento da Educação Física como componente curricular no ambiente escolar, permitindo a valorização dos professores de Educação Física como sujeitos que podem contribuir para a aprendizagem e desenvolvimento dos alunos, de acordo com o projeto pedagógico da escola.

A esse respeito, Trajano (2015) aborda que o Pibid entrelaça os caminhos entre a universidade e a escola, travando discussões acerca da realidade escolar e permitindo o reconhecimento da Educação Física como disciplina escolar. Ribeiro, Afonso e Cavalli (2013) destacaram que as vivências proporcionadas aos futuros professores no âmbito do Pibid Educação Física nos anos iniciais do Ensino Fundamental, em que se depararam com um professor uni docente assumindo a disciplina de Educação Física e ensinando basicamente o conteúdo esportes (futebol e vôlei), levaram a reflexões que contribuíram para que os próprios profissionais da escola refletissem sobre a visão errônea e limitada sobre a Educação Física, mostrando-lhes que o ensino da disciplina vai além do conteúdo esportes e da valorização técnica dos sujeitos. 


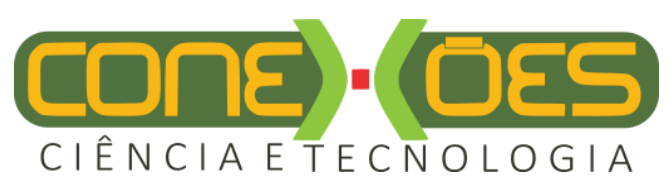

Com isso, há que se retomar brevemente a discussão do tópico anterior que abordava sobre o histórico da Educação Física (EF), retratando que em um determinado período da nossa história, em virtude da influência política e social do regime militar que impactou a estruturação dessa disciplina na escola, usando-a como propagadora da ideologia dominante da época, tendo o esporte como conteúdo hegemônico. Assim, cabe dizer que ainda hoje há uma dependência da Educação Física frente ao conteúdo dos esportes.

De acordo com Ribeiro, Afonso e Cavalli (2013), por meio do Pibid há possibilidades de estimular uma reflexão sobre a visão equivocada da área que ainda é reproduzida em muito dos discursos e práticas da comunidade escolar e da sociedade em geral.

Pode-se mencionar ganhos também quanto à reflexividade docente, tendo em vista que a experiência com o Pibid leva ao reconhecimento da importância do planejamento para a concretização da prática docente, pois ao planejar (RAUCH; FRANTZ, 2013). A esse respeito, Welter, Welter e Sawitzki (2012) encontraram, a partir da análise dos discursos dos bolsistas pibidianos da Educação Física, a compreensão do caráter indispensável que o planejamento assume na via pedagógica dos profissionais do magistério.

Além disso, os achados de Lima (2015) levam à conclusão que o Pibid colaborou para a formação prática dos licenciandos, pois ensina o estudante a entrar na rotina docente, adotando hábitos essenciais para um profissional do magistério, apresentar preocupação didática, manter boas relações com alunos, saber entonar a voz, desenvolver pesquisa, entre outros.

Além disso, a contribuição financeira oferecida pelo Pibid constitui um estímulo à permanência do estudante na universidade, já que os gastos com alimentação, transporte, estadia, xérox, entre outros, levam muitos a desistir do curso antes de sua conclusão. Nesse sentido, Ribeiro, Afonso e Cavalli (2013) concluem que o incentivo financeiro ao longo do curso de graduação pode contribuir para a redução do índice de evasão nas instituição de Ensino Superior.

\section{CONSIDERAÇÕES FINAIS}

O Pibid assume importante papel na formação de estudantes das licenciaturas, em especial, como discutido no presente trabalho, os futuros professores de Educação Física. Ao proporcionar o contato antecipado dos acadêmicos com seu ambiente de trabalho e com a rotina da docência (planejamento, postura, entonação da voz, entre outros), o Pibid destaca-se em relação a outras atividades da licenciatura pela presença de incentivo financeiro aos estudantes.

Foi destacado nesse trabalho a contribuição do Pibid na aproximação entre a teoria e a prática na formação dos futuros professores de Educação Física. Além disso, evidenciou-se que a atuação dos bolsistas de iniciação à docência na escola tem um potencial para promover reflexões acerca do reconhecimento da disciplina de Educação Física, modificando visões equivocadas que persistam no ambiente escolar e tendem a desvalorizar o professor dessa área.

O Pibid é uma atividade que desde a sua implantação têm proporcionado experiências exitosas para a iniciação à docência de estudantes dos cursos de licenciatura. Apesar de sua importância, o Pibid não tem sido capaz de atender à totalidade dos estudantes da licenciatura. Dessa forma, ressalta-se a necessidade de investimentos públicos para a melhoria da qualidade das atividades curriculares obrigatórias da licenciatura, como os Estágios Supervisionados e as Práticas como Componente Curricular, ao mesmo tempo, a manutenção do Pibid como atividade complementar, desenvolvido em estreita articulação com as demais atividades da licenciatura.

Compreende-se a necessidade da realização de pesquisas empíricas que possibilitem o conhecimento das inúmeras realidades de implantação do Pibid nas licenciaturas. Indica-se para pesquisas futuras, a percepção que os egressos do curso de Licenciatura em Educação Física possuem sobre as contribuições do Pibid na sua formação.

\section{AGRADECIMENTOS}

À Coordenação de Aperfeiçoamento de Pessoal de Nível Superior Capes - Brasil, que arcou financeiramente e oportunizou a concretização do presente trabalho. Aos coordenadores de área do Pibid IFCE / Educação Física / Limoeiro do Norte, pelos estímulos e orientações para a produção dessa pesquisa.

\section{REFERÊNCIAS}

AMBROSETTI, Neusa Banhara; NASCIMENTO, Maria das Graças Chagas de Arruda; ALMEIDA, Patrícia Albieri; CALIL, Ana Maria Gimenes Corrêa; PASSOS, Laurizete Ferragut. Contribuições do PIBID para a formação inicial de professores: o olhar dos estudantes. Revi. Educação em 


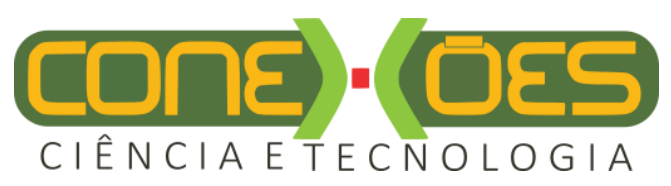

Perspectiva, Viçosa, v. 4, n. 1, p. 151-174, jan./jun. 2013.

ASSIS, A. S. O pibid como política pública para a formação docente. In: $5^{\circ}$ Seminário Institucional PIBID da Universidade Estadual do Rio Grandedo Sul - UERGS, 5; 2016, Rio grande do Sul.

Compartilhar experiências, docência, pesquisa, arte e ambiente. Porto Alegre: Editora da UERGS:2016.

BENITES, Larissa Cerignoni; NETO, Samuel de Souza. Educação Física e formação profissional. Revista Digital - Buenos Aires - Año 10 - № 81 Febrero, 2005.

BETTI, M. Educação física e sociedade. São Paulo: Movimento, 1991.

BRASIL. Presidência da República. Lei 9.394, de 20 de dezembro de 1996. Estabelece as diretrizes e bases da educação nacional. Brasília, DF: Congresso Nacional, 1996.

BRASIL. Presidência da República. Decreto $\mathbf{n}^{\circ}$ 7.219, de 24 de junho de 2010. Dispõe sobre o Programa Institucional de Bolsa de Iniciação à Docência - PIBID e dá outras providências. Brasília, DF: Congresso Nacional, 2010.

CASTELLANI FILHO, Lino. Educação Física no Brasil: a história que não se conta. 18. ed. Campinas, SP: Papirus, 1988.

CASTELLANI FILHO, Lino. Pelos meandros da Educação Física. Revista Brasileira de Ciências do Esporte, Campinas, v.29, n.1, CBCE, p. 119-125, maio de 1993.

DARIDO, S.C. Educação Física na Escola: questões e reflexões. Rio de Janeiro: Guanabara Koogan, 2003.

DARIDO, S. C. Teoria, prática e reflexão na formação profissional em Educação Física. Revista Motriz. v. 01, n.02, 1995, p. 124-28.

FREIRE, João Batista. Educação de corpo inteiro: teoria e prática da Educação Física. São Paulo: Cortez, 1989.

GARCÍA, Carlos Marcelo. Formação de professores para uma mudança educativa $2^{\mathrm{a}} \mathrm{ed}$. Portugal: Porto Editora, 1999.

GHIRALDELLI JÚNIOR, Paulo. Educação física progressista: a pedagogia crítico-social dos conteúdos e a Educação Física brasileira.São Paulo: Loyola, 1991.

LIBÂNEO, J.C. Didática. 15.ed. São Paulo: Cortez, 1999.

LIMA, Maria Elberlene Beserra. Contribuições do Programa Institucional de Bolsas de Iniciação à Docência (PIBID) para a formação prática dos futuros professores de Educação Física: um estudo de caso. Trabalho de Conclusão de Curso (Licenciatura em Educação Física), Instituto Federal de Educação, Ciência e Tecnologia do Ceará (IFCE), campus Limoeiro do Norte, Limoeiro do Norte, 2015.

MARCON, Daniel; NASCIMENTO, Juarez Vieira do; GRAÇA, Amândio Braga Santos. A construção das competências pedagógicas através da prática como componente curricular na formação inicial em educação física. Rev. bras. Educ. Fís. Esp., São Paulo, v.21, n.1, p.11-25, jan./mar. 2007.

MUÑOZ, Susana Inés Segura et al. Revisão sistemática de literatura e metanálise: noções básicas sobre seu desenho, interpretação e aplicação na área da saúde. In: Anais do $8^{\circ}$ Simpósio Brasileiro de Comunicação em Enfermagem, 2-3 maio 2002, Ribeirão Preto, Brasil. Ribeirão Preto: Universidade de São Paulo, 2002. Disponível em:<http://www.proceedings.scielo.br/pdf/sibracen/ n8v2/v2a074.pdf>. Acesso em: 18 maio 2019.

OLIVEIRA, A; BARBOSA, V. S. L. Formação de professores em ciência sociais: Desafios e possibilidades a partir do estágio e do PIBID.

Revista eletrônica Inter-Legere, n. 13, p. 140-162. 2013.

RANGEL-BETTI, Irene C.; BETTI, Mauro. Novas perspectivas na formação profissional em educação física. Revista Motriz. v. 2, n.1, p.10-15, 1996.

RAUSCH, Rita Buzzi; FRANTZ, Matheus Jurgen. Contribuições do Pibid à formação inicial de professores na compreensão de licenciados bolsistas. Atos de pesquisa em Educação - PPGE/ME, v. 8, n. 2, p.620-641, mai./ago. 2013.

RIBEIRO, José Antonio Bicca; AFONSO, Mariângela da Rosa; CAVALLI, Adriana Schüler. Práticas e contextos da formação inicial em educação física. Revista Mackenzie de Educação Física e Esporte, v. 12, n. 1, p. 202-218, 2013.

SOARES, C. et al. Metodologia do ensino da educação física. São Paulo: Cortez, 1992.

SOARES, Carmen Lúcia. Educação Física: raízes européias e Brasil. 4. ed. Campinas, SP: Autores Associados, 2007.

STANZANI, Enio de Lorena; BROIETTI, Fabiele Cristiane Dias; PASSOS, Marinez Meneghello. As Contribuições do PIBID ao Processo de Formação Inicial de Professores de Química. Revi. Química nova na escola, v. 34, n. 4, p. 210-219, Nov. 2012.

TARDIF, Maurice. Saberes docentes e formação profissional. Petrópolis, RJ: Vozes, 2002. 


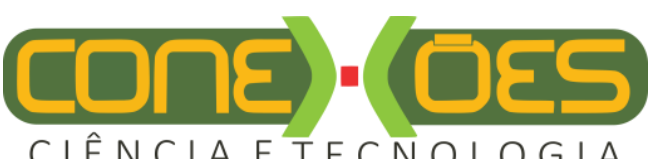

CIÊNCIA E TECNOLOGIA

TRAJANO, Karla Maria Sousa. Pibid e a formação do professor de educação física: uma experiência vivida. V Encontro de Iniciação à Docência da Universidade do Estado do Pará (UEPA), 2015.

WELTER, Jaqueline; WELTER, Renata; SAWITZKI, Rosalvo Luis. A contribuição do subprojeto Pibid/edf No processo de planejamento das aulas de Educação física para os anos iniciais. Cadernos de Formação RBCE, p. 87-96, mai. 2012. 